NBER WORKING PAPER SERIES

ECONOMIC FLUCTUATIONS AND PSEUDO-WEALTH

\author{
Joseph E. Stiglitz \\ Working Paper 28415 \\ http://www.nber.org/papers/w28415 \\ NATIONAL BUREAU OF ECONOMIC RESEARCH \\ 1050 Massachusetts Avenue \\ Cambridge, MA 02138 \\ January 2021
}

Institute for New Economic Thinking The views expressed herein are those of the author and do not necessarily reflect the views of the National Bureau of Economic Research.

NBER working papers are circulated for discussion and comment purposes. They have not been peer-reviewed or been subject to the review by the NBER Board of Directors that accompanies official NBER publications.

(C) 2021 by Joseph E. Stiglitz. All rights reserved. Short sections of text, not to exceed two paragraphs, may be quoted without explicit permission provided that full credit, including ()$^{\circ}$ notice, is given to the source. 
Economic Fluctuations and Pseudo-Wealth

Joseph E. Stiglitz

NBER Working Paper No. 28415

January 2021

JEL No. B22,E03,E21,E44,E60,G01,G12,G18

\begin{abstract}
$\underline{\text { ABSTRACT }}$
What can explain the large changes in aggregate demand that occur in the absence of any seemingly corresponding shock to the underlying state variables of the economy? We show that macroeconomic volatility can arise from dispersions of beliefs among agents. These dispersions give rise to bets and other trades in speculative assets. Such trades give rise to pseudo-wealth, wealth that individuals believe they have on the basis of expectations of returns on these gambles. In the aggregate, when there are enough opportunities for trade and large enough dispersions in beliefs, this perceived wealth may be dangerously untethered from either market wealth or the real wealth of the economy. Given the increased dispersion in beliefs that naturally arises from unprecedented shocks, the theory of pseudo-wealth provides new understandings of both the origins of unanticipated fluctuations and their magnitude, markedly different from prevailing theories grounded in common knowledge and beliefs among individuals. This paper explores the empirical and theoretical underpinnings of pseudo-wealth, links the concept to observed macroeconomic fluctuations, and lays out a research agenda that might help us better understand the role of pseudo-wealth and the circumstances in which it is pronounced.
\end{abstract}

Joseph E. Stiglitz

Uris Hall, Columbia University

3022 Broadway, Room 212

New York, NY 10027

and NBER

jes322@columbia.edu 


\title{
Economic Fluctuations and Pseudo-Wealth
}

\author{
Joseph E. Stiglitz ${ }^{1}$
}

A new view of macro-economic dysfunction shifts the locus of attention from the role of rigid wages to the discordance between the magnitude of changes in aggregate demand and the sluggishness of adjustments, particularly of wages and prices, in a decentralized economic system. After all, wages are not rigid-they fell by some one-third in the Great Depression. And there are high levels of unemployment in developing countries with weak or no unions and little or no job protections. The danger of focusing on wage rigidities is that it leads to an obvious prescription: make wages more flexible. But as the $25 \%$ reduction in wages in Greece in the aftermath of the 2010 crisis made evident, such a large reduction in wages almost surely was a contributing factor in the economic depression that followed. Guzman and Stiglitz (2020b) explain why decentralized nominal wage reductions may indeed lead to severe economic downturns, and can be disequilibrating. ${ }^{2}$

\section{Expectations and animal spirits}

In this new approach, attention is shifted towards explanations of large changes in aggregate demand in the absence of any seemingly corresponding shock to the underlying state variables of the economy-there is no war that devastates; prior to 2020, no pandemic; no news that could account for the magnitude of some of the observed changes. (Indeed, what one might have thought of as important news affecting future prospects of the economy-faster than expected climate change-seems to have had little impact.)

Earlier economics literature, from Keynes on, focused on large changes in expectations as driving changes in aggregate demand-animal spirits, the sudden belief that the future is brighter than previously thought leads to a corresponding sudden increase in consumption and investment.

\footnotetext{
${ }^{1}$ University Professor, Columbia University. This paper is based on joint work with Martin Guzman, and represents an application of ideas developed in Guzman and Stiglitz (2020a). Research assistance from Parijat Lal and Victoria Mooers and financial support from INET are gratefully acknowledged.

${ }^{2}$ Keynes himself was explicit in arguing that nominal wage reductions would not solve the problem of cyclical unemployment.
} 
There is something fundamentally unsatisfactory about such an explanation; it says, in effect, that we can't explain what is going on-that depends on some deep enquiry into the psychology of, say, entrepreneurs, another discipline. Economists can only analyze the consequences of these seemingly random and inexplicable changes in beliefs.

More recently, President Obama seems to have taken the animal spirits theory seriously, inspired by Akerlof and Shiller (2015), trying to manipulate beliefs, by having his economics team talk about green shoots. It didn't work, perhaps not surprisingly. Market participants knew that he and his advisors wanted to "change the narrative," and this undermined the credibility and impact of what they said. ${ }^{3}$ It was just a more sophisticated version of what those in the financial sector had long emphasized-the importance of instilling "confidence," which (they argued) would only be achieved through reducing deficits. The new narrative looked more broadlytalking about "green shoots."

\section{Unanticipated shocks keep happening: Going beyond DSGE}

In recent decades, economists indoctrinated in the belief that individuals are rational have discounted such theories; those theories seem untethered from the data-expectations should be based on past data, and rational individuals doing so won't suddenly change their expectations. But that interpretation of economic behavior-even of rational behavior-is too narrow, and models based on that interpretation (such as real business cycle theories and DSGE, dynamic stochastic general equilibrium, models) have not done well, especially at the critical points of time when the predictions and prescriptions of the models are of such importance, say in the years surrounding the 2008 crisis. And for good reason: those events are almost always "out of equilibrium" events, unanticipated events where contracts are broken, plans not fulfilled. Guzman and Stiglitz (2020b) have formulated another approach, the dynamic disequilibrium model with noise.

\footnotetext{
${ }^{3}$ It might have been the case that there were multiple equilibria, and the Administration was trying to get the economy coordinated on a good equilibrium.
} 
In a world that is always evolving, never stationary, with large events and ideas that were not contemplated always occurring, economic agents are always struggling to interpret the "news," to understand the implications for the future. Those moments of crises are moments when past data give us uncertain perspectives on the future, and so different individuals, looking at the same past behavior, may well come to different views about what lies ahead.

There are several aspects of this expectations formation process that are crucial. First, as we have just noted, different individuals come to different views. There is extensive heterogeneity in beliefs. Most of this paper is concerned with the evidence behind that statement and the implications. Theorems saying that individuals, as they exchange information, come to have "common knowledge" - a state of affairs in which all individuals agree about the probabilities of different events, a set of shared beliefs-clearly don't apply. ${ }^{4}$ It is an important question why that is so; but for this paper, we do not need to answer that question.

But while they don't come to a set of shared beliefs, individuals do look to each other, both because each individual knows his information is incomplete, and therefore others' views can complement his information set; and because individuals know that there may be flaws or biases in his information processing. Besides, humans are social beings, and part of human sociability is exchanging views.

Because, in general, others' views affect one's own, there can be herding behavior-sometimes referred to as "group think." And group think can give rise to large social multipliers: optimism and pessimism can be contagious; as optimism by one group, leading to more consumption and investment, spreads to others, the overall increase in aggregate will be much larger than it would have been in the absence of such contagion. Such herding behavior can even be, in some sense, rational, as individuals incorporate into their beliefs signals concerning information about others' information embedded in their actions. ${ }^{5}$ There can be a wave of optimism or pessimism through

\footnotetext{
${ }^{4}$ Aumann (1976) provides among the first formal definitions of common knowledge in economics.

${ }^{5}$ Devenow and Welch (1996) provide a review of papers on the economics of rational herding in financial markets, and Zhang and Liu (2012) provide evidence for this from microloan markets in the United States. See also Banerjee
} 
an economy, a wave not perfectly justified by past evidence but which may be at least partially self-justifying, i.e. the optimism leads to more investment and consumption, which justifies the optimism. Individuals don't have precise expectations; it's not as if their actions are based on beliefs of growth of $4.25 \%$, and then, when it turns out that growth is $4.21 \%$, they say, ah, my model was wrong; but rather their beliefs are that growth will be, say, greater than $3 \%$, and when it turns out that it was $4.21 \%$, they say, ah, my views of the world are correct.

When individual's beliefs are highly interdependent, beliefs can be very unstable: they can change quickly from very optimistic to very pessimistic, on the basis of certain "news" that neither ex ante nor ex post would seem to justify the magnitude of the shift in beliefs.

Widespread changes in such beliefs can induce large changes in aggregate demand, larger than can perhaps be rationally justified by any news, but more importantly for our purpose, larger than can be easily accommodated by the sluggish adjustment processes that characterize a decentralized economy. ${ }^{6}$

The key role of dispersion in beliefs

This paper is concerned with another dimension of beliefs that has been swept under the rug in the rational expectations modeling that has dominated the literature in recent decades. There are large dispersions in beliefs - there is not common knowledge, an assertion which should be obvious to anyone, but the maintained hypothesis in most macro modeling is that this is not the case. Any micro-founded macroeconomics has to come to terms with why that is so and its consequences. In two earlier papers, Guzman and Stiglitz (2015, 2020a) have argued that changes in the magnitude of dispersion in beliefs and opportunities to engage in trades based on that dispersion can give rise to fluctuations in aggregate perceptions of wealth, in indebtedness,

(1992), Bikhchandani et al 1992 and Caplin and Leahy (1993). Additionally, see Trueman (1994) and Clement and Tse (2005) on herding behavior specifically in the context of analyst forecasts.

${ }^{6}$ There is a large literature explaining why price and quantity adjustments will be sluggish. Macro economists have relied on Calvo-style staggered contracts and menu costs, but probably more important is that in the presence of uncertainty and risk aversion, optimal behavior entails sluggish adjustment, enabling one to learn more about the environment. See Greenwald and Stiglitz (1989). 
and in aggregate consumption. Guzman and Stiglitz refer to the wealth that individuals believe they have on the basis of expectations of returns on gambles, such as bets with others or investments in risky assets, but which in the aggregate may be untethered to the real wealth of the economy, as pseudo-wealth. ${ }^{7}$ They argue that the existence of pseudo-wealth is an important but neglected feature of any economy in which there is not common knowledge, i.e. in which individuals differ in their beliefs.

Pseudo-wealth has its origins in economic transactions that are an inherent part of an economic system characterized by agents with heterogeneous beliefs-pseudo-wealth is an endogenous outcome of a market economy that provides opportunities for agents with different beliefs to create assets or liabilities. These include not just betting opportunities, but any financial transaction in which payments are defined over states ${ }^{8}$ and beliefs about the probability of the occurrence of these states may differ across individuals.

Changes in the extent of dispersion of beliefs, and the ability and willingness to engage in "effective bets" on those differences (a concept which will be explained in greater detail in section 1, but for the moment can be thought of as simply financial transactions engendered by differences in beliefs), give rise to fluctuations in aggregate pseudo-wealth, and with aggregate demand, and especially consumption, related to aggregate wealth perceptions, fluctuations in aggregate pseudo-wealth naturally give rise to economic volatility.

\section{Pseudo-wealth and market wealth}

There can be marked disparities between pseudo-wealth and market wealth, and between both of these and any "true" estimate of the wealth of the economy-and this, as we shall see, itself has important implications for economic fluctuations. Changes, say in markets or regulations,

\footnotetext{
7 There is a literature addressing the question of the impact of heterogenous beliefs on market prices and therefore market wealth in the presence of constraints on short sales. By contrast, we are concerned here with perceived wealth. See fn. 28 and the preceding discussion below.

${ }^{8}$ Not necessarily Arrow-Debreu (AD) states of nature: contracts can be defined over variables which depend on the underlying $A D$ states. For instance, financial instruments may have payouts that are a function of profits or market value, which themselves are a function of the underlying states of nature.
} 
can reduce the volatility of market wealth but increase that of pseudo-wealth. Aggregate demand depends on both: pseudo-wealth reflects individuals' (beliefs about their) opportunity set, and therefore should drive consumption. But in a world of imperfect and asymmetric information, where there may be credit rationing and collateral constraints may be binding, market wealth can also be an important determinant of aggregate demand. Depending on the circumstances, changes in one or the other may be more important; understanding empirically the relative importance of each in different circumstances should be an important part of the empirical agenda going forward. ${ }^{9}$

Changes in pseudo-wealth are related to the increased dispersion in beliefs which naturally arises from moments, such as new discoveries, new political movements, and severe downturns, associated with the "unexpected," the implications of which are hard to forecast. These moments almost always have something in common with the past, but the question is, how much? Those advocating for some of these changes, such as the financial innovations of the latter part of the $20^{\text {th }}$ century and the beginning of this century, herald them as ushering in a new world. If so, reliance on data from the past is of questionable value. But it is often in these champions' self-interest to so characterize them; others will see the world in more evolutionary terms. The quandary that this puts both analysts and ordinary citizens in-and the near schizophrenia to which it gives rise-is illustrated by the financial innovations to which I just referred. While the champions of these innovations claimed that the new financial products enabled markets to better spread and share risks, making the economy more stable and the financial products correspondingly safer, to evaluate the risk of these products, they used data from the pre-innovation era. But the "innovation" had in fact ushered in an era of fraud and moral hazard, so the quality of loans issued was markedly lower than those of the earlier era. In the early years of the century, there simply wasn't the data to ascertain that that was the caseany model based on past data was clearly irrelevant. Of course, some analysts recognized that

\footnotetext{
${ }^{9}$ As section 4 below emphasizes, consumption (and more broadly aggregate demand) is also a function of perceived uncertainty, and the situations in which there are increases in dispersions of beliefs may also be circumstances in which there are increases in uncertainty, making the challenge of parsing out the role of market vs. pseudo-wealth all the more difficult.
} 
there had been a change in incentives, and that the change in incentives likely would change outcomes. Others looked to the design of untested contract provisions-at least untested under these circumstances-to provide adequate incentives. ${ }^{10}$ There was no way at the moment to resolve the differences in views: the new financial products accordingly gave rise to disparate beliefs about what would happen, disparate beliefs that could and did give rise to pseudowealth-and this pseudo-wealth played a role in accelerating the boom and bubble. ${ }^{11}$

Kindleberger (1978) has closely studied the booms and bubbles and the associated busts and panics that have characterized capitalism over the centuries. New technologies, innovations, are at the center of most, and for good reason. There is inevitably a burst of optimism among some about the potential of such technologies. The theory of pseudo-wealth helps us understand better the above "excesses" associated with such events; it says that even if on average citizens are correct in their estimates, the inevitable dispersion in beliefs can unleash and/or accelerate a boom.

Pseudo-wealth can also help explain downward movements in the economy. There can be negative pseudo-wealth, where the amount debtors believe that they will repay creditors exceeds what creditors believe that they will receive. This disparity increases after the breaking of a bubble; the resulting decline in aggregate pseudo-wealth contributes to the depth of the recession.

Guzman and Stiglitz $(2015,2020)$ thus argue that the theory of pseudo-wealth provides a better understanding of both the origins of fluctuations and their magnitude: in some cases, pseudowealth serves to amplify fluctuations originating from other sources; in other cases, the fact that

\footnotetext{
${ }^{10}$ In particular, what was called the "put back provision," where mortgages that were defective were put back to the mortgage originator; it was, in effect, a money-back guarantee that the mortgages were as they were represented to be. As it turned out, virtually all the large financial institutions issuing these guarantees refused to honor them, and only did so after long and expensive litigation.

11 There is a wealth of analytic and popular writing describing this episode, including Stiglitz (2010a, 2010b), Gai, Haldane, and Kapadia (2011), Geanakoplos et al. (2012), and Wolf (2014), among others.
} 
pseudo-wealth can exceed market and actual wealth by a considerable amount can itself be the source of the economic disturbance.

We suggest, in particular, that the events at the center of Guzman and Stiglitz's (2020b) analysis of dynamic disequilibrium models with noise-where macro-economic inconsistencies get revealed, where significant numbers of market participants come to realize (or believe) that previously made plans can't be realized, e.g. large numbers of households realize that their consumption plans are not feasible-are moments in time marked by large changes in the dispersion of beliefs and thus potentially in pseudo-wealth, which may amplify the consequences of the disturbances that occur at those moments. These are moments in which there can be a sudden change, not just in those plans, but also in agents' understandings about the economy.

\section{Pseudo-wealth as a source of perturbations}

At the same time, pseudo-wealth can itself be a source of perturbations: The very fact that pseudo-wealth may exceed actual wealth by a significant amount means that plans cannot be consistent. At some point, there will have to be a revision. Whether those revisions are smooth-a succession of small revisions that can be accommodated without a crisis-or sudden, and thus crisis inducing, depends on the disparity between pseudo-wealth and actual wealth and the rate of change of the disparity between the two, as well as on the processes of social contagion of beliefs. ${ }^{12}$

This paper explores further the empirical and theoretical foundations of the theory of pseudowealth and attempts to link pseudo-wealth more closely to macroeconomic fluctuations. It does not provide a full-blown test of the relevance of the theory, e.g., ascertaining the fraction of large macroeconomic fluctuations associated with fluctuations in pseudo-wealth or identifying particular fluctuations in which pseudo-wealth played a dominant role.

\footnotetext{
${ }^{12}$ It is important to emphasize that while it is almost inevitable that pseudo-wealth will give rise to macroeconomic inconsistencies, macroeconomic inconsistencies can arise much more generally whenever there are incomplete markets or contracts (that is, always).
} 
Its task is more modest: to lay out some of the ingredients of a research agenda that might help us understand better the role of pseudo-wealth in economic fluctuations; to review the evidence on the importance of beliefs heterogeneity and some indirect theory and evidence suggesting why it is plausible that pseudo-wealth could have large effects, to identify circumstances under which one might expect pseudo-wealth to play an important role, i.e. not only to explain why dispersions in beliefs might persist, but to identify the circumstances in which dispersions in beliefs might increase or decrease, giving rise to fluctuations in pseudo-wealth which in turn give rise to fluctuations in aggregate demand.

There are thus seven intertwined pillars in the theory of macroeconomic fluctuations which we have been developing: (a) The stochastic processes describing the evolution of the economy are not stationary; there are always unanticipated events-events which couldn't be anticipated; (b) accordingly markets and contracts are inherently incomplete; (c) individuals inevitably have different views about the future-there is not common knowledge; in particular, they have different interpretations of key events that mark the evolution of our economy and society; (d) differences in views give rise to pseudo-wealth; (e) in the absence of a complete set of markets, there must necessarily arise moments of macroeconomic inconsistency, with economic plans and contracts being broken - these are often moments of crisis and deep downturns; (f) pseudowealth can exacerbate the magnitude of the macroeconomic inconsistencies; (g) moments at which such inconsistencies get revealed (or when it becomes widely understood that there are such inconsistencies) spark a widespread awareness that previous beliefs were, in some fundamental and deeply relevant sense, wrong, and individuals have to form new world views, and as they do that, there will be an increased dispersion in beliefs, giving rise to the possibility, or even likelihood, of marked changes in aggregate pseudo-wealth.

This set of explanations of fluctuations stands in marked contrast to that underlying real business cycle theory, or even dynamic stochastic general equilibrium theories, where the stochastic processes are stationary, there is common knowledge-no dispersion in beliefs-and while contracts are not complete, neither are they ever broken; there are never any macroeconomic 
inconsistencies; and when they happen-crises do occur, events that are outside the modelmarket participants forge ahead, reaffirming their belief in equilibrium analysis, behaving as if there will never be another instance in which such an event occurs. In the most popular versions, based on the representative agent model, the absence of markets and the incompleteness of contracts does not matter at all, since no trade occurs in markets and there are no meaningful contracts.

\section{Outline of paper}

The paper has seven sections beyond this introduction and the conclusion. In the first, we describe the many forms of pseudo-wealth-how it arises in a multiplicity of asset and financial transactions. The second and third sections look at both the direct and indirect evidence on the lack of common knowledge, the existence of significant dispersions in beliefs, and how such dispersions can persist. The fourth section discusses circumstances in which differences in beliefs may not give rise to pseudo-wealth, or may do so only to a very limited extent. The fifth and sixth sections then connect pseudo-wealth to macroeconomic fluctuations. The seventh section outlines an empirical research agenda.

\section{The many forms of pseudo-wealth}

The basic intuition behind the theory of pseudo-wealth is simple: If individuals differ in their beliefs, they will engage in trade-for instance, by making bets (later in this section, we will note a wider range of opportunities for trade based on dispersions in beliefs). Each participant in the bet believes it will win (on average) and so the sum of the individuals' perceived wealth exceeds the wealth of the economy. A well-documented empirical regularity is that an individual's consumption depends on their wealth (Fair, 2020); indeed, any standard theory with individuals maximizing utility subject to a budget constraint has consumption today increasing with perceived wealth, holding all else constant. ${ }^{13}$ If there are changes in the magnitude of disparities in beliefs or in the opportunities or the willingness to "bet" on those differences, then there will

\footnotetext{
${ }^{13}$ Except for individuals who face borrowing constraints.
} 
be fluctuations in aggregate pseudo-wealth. There is a presumption that if aggregate (perceived) wealth fluctuates, aggregate consumption will fluctuate. And it is easy to construct models where the impact of this fluctuation in aggregate consumption is amplified through macroeconomic externalities, as we discuss more fully in sections 5 and in 6 .

Aggregate pseudo-wealth will vary with an increase or decrease in "open bets," and that will be affected by the dispersion of beliefs. When the economy is behaving smoothly, say, during the Great Moderation, there may be widespread consensus on how the economy functions. But when an event that was not widely anticipated, or even more strongly, was believed to be virtually impossible under prevailing beliefs about the economy, such as the creation and then breaking of the housing bubble, there is likely to be an increase in the dispersion of beliefs, as different individuals "read" into the situation different lessons: some see a bubble; others do not; some blame the Fed for maintaining interest rates at too low of a level, others blame not fully rational and excessively greedy and short-sighted market participants, some blame the regulator for doing too little, some for doing too much, some look to structural flaws in decision making and corporate governance that lead to excessive short sightedness. Disagreements abound, and whenever there are disagreements, there are opportunities for bets.

The simplest source of pseudo-wealth is that generated by the bets just described. But pseudowealth arises even when there are not formal bets, simply as a result of structured finance. In each of the situations described below, we assume that beliefs are on average correct. Thus, in a world where demand curves for assets were linear in returns, the price would reflect average expectations - that is, would perfectly reflect underlying returns. While with non-linear demand functions there would be some deviation from this, the departure of aggregate perceived wealth from this benchmark with which we are concerned in this paper are much larger. Below, we illustrate with four examples.

(a) Assume there are two types of individuals $A$ and $B$, and two assets, $\alpha$ and $\beta$. A believes $\alpha$ yields $\bar{Y}+\Delta$, while $\beta$ yields $\bar{Y}-\Delta$, and conversely for B. A will buy $\alpha, \mathrm{B}, \beta$, so that aggregate perceived wealth is $\overline{2 Y}+2 \Delta$, potentially far in excess of aggregate wealth. An 
increase in dispersion here means an increase in $\Delta$ : the larger $\Delta$, the greater the value of perceived wealth $\Delta$. A change in beliefs, where $A$ now believes that $\beta$ will do better in the future by $\Delta$ (for a total change in beliefs of $2 \Delta$ ), and conversely for $B$, leads $A$ and $B$ to trade their assets. These are purely speculative trades, based on changes in beliefs (and explored further in the next section). This trade itself leads to an increase in the value of aggregate pseudo wealth (compared to the previous situation) of $4 \Delta$, a change in perceived wealth that (with similar changes in others engaging in trade) can have macroeconomic consequences.

(b) Short sales. This assumes no short sales. If $A$ and $B$ can engage in short sales, $A$ will hold negative amounts of $\beta$, and conversely for $B$, and their aggregate (perceived) wealth will be much larger. ${ }^{14}$ At the same time, allowing short sales lowers the market value of shares-without short sales, type $\mathrm{A}$ bids up the price of $\alpha$ to $\bar{Y}+\Delta$ (if they are risk neutral), and similarly for $\beta$; but with short sales, the prices of both assets will fall. If we assume that on average individuals are rational (i.e., the true value of each asset is $\bar{Y}$ ) then allowing short sales reduces the disparity between market wealth and true wealth, but increases the disparity between pseudo-wealth and both market wealth and true wealth-a disparity that can have strong macroeconomic consequences. ${ }^{15}$

(c) Financial structuring. Assume now that there is only one asset, and that the two groups of individuals differ in their view of the returns on that asset, with $A$ believing the returns to be $\bar{Y}+\Delta$ and $\mathrm{B}$ believing them to be $\bar{Y}-\Delta$. The corporation raises funds by issuing bonds to $\mathrm{B}$, committing them to pay a fixed amount $\mathrm{R}$, equal to say $\lambda \bar{Y}$ (assumed to be less than $\bar{Y}-\Delta$ ), with the residual going to the equity holders, $\mathrm{A}$, who (believe they will) get $\bar{Y}+\Delta-\lambda \bar{Y}$, so now aggregate perceived wealth is $\bar{Y}+\Delta$ : it reflects the perspective of the optimists, even though it is only on average that society's judgments are correct. Again, the greater the dispersion, i.e., the greater $\Delta$, the greater perceived wealth. In this case, market wealth as well as perceived wealth increases with dispersion. Competition

\footnotetext{
${ }^{14}$ There is a literature focusing on the impact on market prices (and hence on market wealth) of heterogeneous expectations in the presence of short sales. See the discussion below and in fn. 28.

${ }^{15}$ By the same token, restricting trade (increasing transactions costs) reduces the value of pseudo-wealth. In more general models, it can reduce the volatility in both market wealth and pseudo-wealth.
} 
among the optimists will drive up the value of equity to $\bar{Y}+\Delta-\lambda \bar{Y},{ }^{16}$ so that aggregate market wealth is $\bar{Y}+\Delta$, increasing with the dispersion in beliefs and with perceived wealth.

(d) Debt. Perceived wealth may, of course, be less than true wealth. Debtors may believe they will pay more than creditors believe that they will receive, so there is negative pseudo-wealth. ${ }^{17}$ Consider a debt contract where the debtors believe that they will fulfill their debt contract, and so their wealth is $\overline{Y_{d}}-D$, where $D$ is the debt payment. But the creditors believe that there is a probability $1-p$ that the debtors will pay nothing, so the expected debt payment is $p D$. Then the creditors' wealth is $\bar{Y}_{c}+p D$, so aggregate wealth is $\overline{Y_{d}}+\overline{Y_{c}}-(1-p) D .1-p$ reflects the dispersion in beliefs. The greater the dispersion in beliefs, the greater negative pseudo-wealth.

These various forms of pseudo-wealth interact and play out in different ways in the context of different fluctuations. If people shared the same view (e.g. concerning the growth in housing prices), had the same preferences, and faced the same constraints, then all would take an equity position to reap the gains. To some extent, those who lend money to the equity holders are taking a bet: that the returns won't be as high as the equity owners believe. ${ }^{18} \mathrm{~A}$ financial instrument which trades off income in the good states for income in the bad states can be viewed as a bet, with both parties believing that they are going to win, and this gives rise to pseudo-wealth.

If this interpretation is plausible, it suggests that behind periods of large increases in debt there are often large increases in hidden pseudo-wealth, providing at least part of the explanation for the "boom" aspects of these periods. (Guzman and Stiglitz, 2020a). The contraction that follows the boom-when equity owners discover that the returns are not as high as they thought, and

\footnotetext{
${ }^{16}$ This requires that there be no short sales. If there are, the pessimists will drive down the price of equity. The role of restrictions on short sales is highlighted in some of the research described below.

17 This aspect of debt contracts was first explored in Stiglitz (1972), which provided an early discussion of the consequences of heterogeneous beliefs.

${ }^{18}$ Of course, differences in portfolios are also motivated by differences in risk aversion and differences in holdings of non-traded assets. We comment on the particular role played by differences in beliefs later in this paper.
} 
debt holders discover that matters are even worse than they thought-is associated with a collapse of pseudo-wealth and a conversion of positive into negative aggregate pseudo-wealth.

We have also noted that dispersions in beliefs can lead to an increase in market wealth. As we noted earlier, what matters for consumption today for individuals who are not credit constrained is perceived wealth, not market wealth ${ }^{19}$; but what matters for credit constrained individuals is market wealth, not perceived wealth. Similar arguments hold for firms: a firm that believes it is wealthier (has more pseudo-wealth) may be more willing to bear risk and invest; but a firm whose balance sheets have improved, for instance as a result of an increase in the value of its assets, may be both more willing and more able to invest. ${ }^{20}$ In a world with financial market frictions, with credit and equity rationing, an increase in wealth can increase the ability and willingness of individuals and firms to borrow ${ }^{21}$, and of banks and other financial institutions to lend (see Greenwald and Stiglitz, 2003), thereby increasing investment.

This paper focuses in particular on the role of pseudo (perceived) wealth and its fluctuations in macroeconomic volatility. And when we refer to pseudo-wealth and its volatility, we do so comprehensively, through all the mechanisms described above, and perhaps others.

\footnotetext{
${ }^{19}$ Matters are slightly more complicated: the interest rate at which individuals can borrow will be a function of the value of the collateral they can provide and/or the value of the assets that lenders believe they can seize in bankruptcy. This can affect individuals' consumption today, especially when there are disparities in beliefs about the value of these assets in the future, at the time when the default occurs. See, e.g. Stiglitz (1972) and Greenwald and Stiglitz (1993).

${ }^{20}$ The latter statement itself is a marked departure from the neoclassical theory of investment, which emphasizes only future prospective marginal returns relative to the cost of capital. It is predicated on the existence of capital market imperfections of the kind emphasized by Greenwald and Stiglitz (1993, 2003).

${ }^{21}$ See, for instance, Stiglitz and Weiss (1981, 1986, 1992), Kiyotaki and Moore (1997) and Greenwald and Stiglitz (1993). Of course, asymmetries of information imply dispersions in beliefs (knowledge). The differences in beliefs with which we are concerned here are markedly different from those emphasized in the earlier literature on information asymmetries.
} 


\section{Direct and Indirect Evidence on the lack of common knowledge}

There is ample evidence of (a) the lack of common knowledge and differences in beliefs; (b) the persistence of differences; (c) changes in those differences over time; and (d) differences in beliefs mattering for economic outcomes. ${ }^{22}$

Differences in prior beliefs and in the interpretation of the evidence available could arise from different experiences and exposures, as well being the consequence of behavioral biases (like confirmation bias) that have been extensively investigated by behavioral economists. For our analysis, what matters is that beliefs differ, independently of what creates those differences.

The evidence is both direct and indirect, both macroeconomic and microeconomic.

Direct evidence is provided by survey results about expectations. ${ }^{23}$ Surveys substantiate large differences in beliefs in a whole host of areas. See Fetzer et al. (2020), for instance, on the dispersion of beliefs about coronavirus risk factors and economic anxieties. (In the next sections, we explain why we should not be surprised by such dispersion and its persistence.)

Dispersion is strong even among experts: In January 2018, the disparity between the bottom 10 "blue chip" GDP growth forecasts for 2019 and the top 10 was almost 50\%. ${ }^{24}$ There was no evidence of "common knowledge," even among this group of experts who are supposed to have access to and process all available information. There is also evidence that different groups within society process information differently, and so come to different beliefs, e.g. about

\footnotetext{
${ }^{22}$ Dispersion in beliefs can have macroeconomic consequences through different channels. If consumption is not a linear function of wealth, then aggregate consumption will be a function of wealth dispersion-including, as emphasized here, of the dispersion in pseudo-wealth. If consumption is not a linear function of the real interest rate, dispersion in beliefs about the real interest rate will affect aggregate consumption. Tsiaplias (2020) provides evidence, for instance, of the variation over time in dispersion about beliefs about inflation among consumers. As we emphasize below, however, the effects with which we are concerned are different and likely to be larger and more variable that these aggregation effects.

${ }^{23}$ See Hamermesh (1985) on subjective expectations and probabilities of survival, Manski and Straub (2000) on varying worker perceptions of job insecurity, Fisman and O'Neill (2009) on gender differences in beliefs on the returns to effort, and Beber, Breedon, and Buraschi (2010) on differences in beliefs based on currency forecasts, among others.

${ }^{24}$ For a more extensive discussion of forecaster disagreements, see Dovern et al 2012.
} 
inflation or GDP. Guzman (2010b), for instance, provides evidence on different expectations by gender.

Persistent dispersion in beliefs is, indeed, a pervasive feature of market economies, though the magnitude of dispersion may change over times. ${ }^{25}$ See, for instance, Patton and Timmermann (2010) on persistence and changes in differences in views among economic forecasters. Jiang and Sun (2014) document both different levels of and changes in the dispersion in beliefs among mutual funds. Bamber, Barron, and Stober (1997) look at changes in the dispersion of beliefs among investors before and after earnings announcements.

While at one time, economists expressed skepticism about the relevance of information obtained from surveys ("just words"), a host of studies have shown that the data produced by surveys is economically significant. Beliefs as reflected in surveys matter for both microeconomic and macroeconomic behavior, and the explanatory power of survey data is receiving increasing recognition. This view has been forcefully defended, for instance, by Gennaioli and Shleifer (2018). Giglio et al. (2019) not only document persistence of heterogeneity of beliefs, but also provide evidence on the link between beliefs revealed by surveys and real actions taken by survey respondents (the analysis focuses on a sample of U.S.-based clients of Vanguard, one of the world's largest asset management firms). Guzman (2010a), among others, shows that introducing information from surveys improves the predictive performance in macroeconomic models. ${ }^{26}$

\footnotetext{
${ }^{25}$ The only circumstances in which one would expect there not to be dispersion in beliefs are those in which markets are informationally efficient. Grossman and Stiglitz (1980) showed that markets are essentially never informationally efficient-if they were, no one would pay to obtain information; there was always dispersion in beliefs. Shiller, in a series of papers (partially summarized in Shiller 2014) provided convincing empirical evidence.

${ }^{26}$ Kaufmann and Scheufele (2017) show this for a business tendency survey for Switzerland. Fuhrer (2017) embeds survey expectations in a standard DSGE (in typical versions of which individuals have rational expectations, so beliefs incorporate all past data), and shows that doing so improves the identification of key parameters and that slow-moving expectations does a better job of accounting for the persistence in aggregate data than other explanations, including autocorrelated shocks.
} 


\section{Trading volumes}

A body of evidence on dispersion in beliefs particularly related to our theory of pseudo-wealth concerns the large trading volumes in asset markets and large bets that occur in derivative and credit default swaps markets. The extent and nature of this trading is hard to explain based solely on (changes in) individual circumstances, e.g. it is greater than can be accounted for by changes in the value and risk characteristics of individuals' holdings of non-tradeable assets, such as their human capital. (Stiglitz, 1982, also notes that if what was driving portfolio allocations were attempts to hedge changes in human capital, the information provided by financial intermediaries would be markedly different from that which is provided.)

Indeed, in the absence a dispersion of beliefs, with fixed non-traded assets (human capital), there would be no speculative trade. Differences in priors are a necessary condition for speculative trade, i.e., trade that is unrelated to differences in preferences, endowments, or constraints. In models with heterogeneous information but common priors, no-trade theorems apply (Milgrom and Stokey, 1982; Stiglitz, 1982), unless rationality is not common knowledge (Neeman, 1996).

The magnitude of trading volumes is consistent with dispersions in beliefs of a kind which could and would naturally give rise to the existence of pseudo-wealth. And fluctuations in those trading volumes is consistent with changes in beliefs and fluctuations in the value of pseudo-wealth. In fact, there is a large empirical literature directly relating dispersion in beliefs with trading volumes. Bildersee, Radhakrishnan, and Ronen (1996) find that trading volume is positively correlated with contemporaneous dispersion of beliefs. Li and Li (2014) also document a robust positive relationship between the belief dispersion among household investors and the stock market trading volume, using more than 30 years of survey data 27.

Not surprisingly, dispersion in beliefs not only affects trading volumes but also market outcomes-implying that even if individuals on average predicted correctly, the fact that they disagree itself has consequences (consistent with the theory being presented here, but not with

\footnotetext{
27 See also Bamber et al (1997).
} 
standard models entailing linear aggregation-but as we have emphasized, the effects with which we are concerned with in this paper go well beyond those associated just with aggregation.) Diether et al. (2002) analyze how analysts' differences of opinion on the earnings forecasts about stocks affect asset prices. Hong and Stein (1999) predict that negative skewness in returns will be most pronounced in periods of more trading volume, and Chen, Hong, and Stein (2001)'s empirical work confirms this pattern in the daily returns of individual stocks. Skewness here captures the empirical fact that big price changes are more likely to be negative rather than positive, or that stock markets "melt down, but they don't melt up," as Chen, Hong, and Stein (2001) put it. Given the positive link between dispersion in beliefs and trading volumes, and in turn the positive relationship between trading volume and negative skewness, the literature suggests that disagreement alone can help us understand the vulnerability of markets to crashes, especially those that occur without an associated large public news event.

\section{Macroeconomics}

If the dispersion of beliefs affects trading in financial assets and outcomes in financial markets, it almost immediately follows that dispersion in beliefs will have macroeconomic consequences.

Notably, Geanakopolis and his co-authors (Fostel and Geanakopolis, 2012, 2013, Geanakopolis, $1989,2003,2010)$ explain excessive volatility of asset prices based on the interaction between heterogeneous expectations, collateral and sale constraints, and leverage. ${ }^{28}$ Bad news in the economic environment can be amplified through the interaction between leverage and collateral constraints, in a world with endogenously determined contracts, leading to large changes in the "marginal buyer" of an asset, and thus in asset market prices. This in turn has macroeconomic consequences, leading to a leverage cycle. ${ }^{29}$ Note that these theories are strongly complementary to that developed here: in both, dispersions in beliefs are central. The theories

\footnotetext{
${ }^{28}$ For a somewhat different approach, see Scheinkman and Xiong (2003).

29 These leverage cycles are markedly different from the credit cycles discussed at the end of the previous section, in which there are asymmetries of information, but not dispersions in beliefs.
} 
developed here focus on the implications for aggregate consumption and on aggregate investment. $^{30}$

Geanakopolis and related work focused on changes in market wealth. But changes in the dispersion in beliefs, operating through changes in pseudo-wealth-say a willingness of households to borrow and a willingness of banks to lend-can give rise to much the same dynamic. This work shares with ours an emphasis on the importance of the dispersion of beliefs and changes over the cycle in that dispersion. As we noted, however, at the end of the previous section, the channels through which market and pseudo-wealth affect the economy are quite different.

Other macroeconomic phenomena, such as the exchange rate premium, have also been traced to heterogeneity in information and beliefs. (See, e.g. Bacchetta and Wincoop, 2006, Bebr et al, 2010). ${ }^{31}$

\section{Persistence of dispersion}

Not only can there can exist large differences in beliefs, but those differences can be sustained, at least for a while: All that we require is that there is not common knowledge, implying that at least one of the assumptions which give rise to "common knowledge" is not satisfied. ${ }^{32}$

\section{Rare events}

The type of events that are at the core of our analysis are of a kind over which there are not enough opportunities for learning, so that heterogeneity of beliefs can be a persistent feature of

\footnotetext{
${ }^{30}$ As we have noted, as aggregate perceived wealth increases, in general, current desired levels of aggregate consumption increase. Similarly, as the perceived wealth of enterprises increases, their willingness to undertake investment increases and the willingness of financial institutions to make loans increases.

${ }^{31}$ There is a long tradition of looking to forecasting errors as a source of business fluctuations (Pigou, 1926 and more recently, Phelps, 1999). Pseudo-wealth focuses, though, not on average mistakes but on dispersion. More recent literature has shown that such cyclical fluctuations can even be based on rational expectations-but differential beliefs, i.e., a lack of common knowledge, based on differential information. (See Beaudry and Portier, 2004, 2006).

${ }^{32}$ See Milgrom (1981) for a discussion of the conditions under which common knowledge prevails. Kurz (1994) and Kurz and Motolese (2001) provide a general theory for the persistence of heterogeneous expectations, and discuss the role of such heterogeneity in economic volatility.
} 
the environment. These "rare" events are those which occur sufficiently infrequently that there is no way to formulate an objective conditional probability distribution. We might all come to an agreement about the probability distribution of life expectancies, given the large data base. Even if it is the case that the economic system can process well events that are not rare, it is difficult to learn enough about the probability distributions of rare events because by definition we do not get many observations of such events. There is no way that one can formulate an objective distribution of an event of enormous economic consequences, such as the re-election of a demagogue like Donald Trump.

While each such event is rare, in the sense just defined, the occurrence of such "rare" events is not rare, and they are the events which dominate much of our thinking. Such events-whether it's the breaking of a housing bubble, the election of a demagogue, the occurrence of a pandemic- are the kinds of events that give rise to the large economic fluctuations which should be at the center of macroeconomic analysis. And the change in pseudo-wealth that is associated with such events can play an important role in amplifying the consequences of these shocks.

\section{Natural selection}

Some economists have argued to the contrary, that even if the conditions under which there is common knowledge do not hold, those who can more accurately predict the future-those with close to what might be thought of as rational expectations-will predominate. This is sometimes called the natural selection hypothesis, which contends that the financial wealth of agents with incorrect beliefs trends towards zero in the long run.

The economic environments in which the natural selection hypothesis holds are generally distinct from those of concern here, where there is no "objective" probability distribution. If the event over which there is speculative trade is rare, there are not enough opportunities for the agents with the objective beliefs to prevail. 
In reality, of course, some individuals may have better judgments in one area, others in another. They may both have overconfidence in their judgments in areas which are not of their competence. They thus may make profits from bets (investments) in one area, losses in others; but all the while, there may be betting opportunities, with variability in aggregate pseudo-wealth affecting macroeconomic fluctuations.

Even in an economic environment not predominated by rare events, there are plausible conditions under which the natural selection hypothesis fails and the economic system exhibits persistent heterogeneity in beliefs-consistent with what is documented in empirical work on beliefs and with observed economic behavior. Cao (2018), for instance, lays out one model in which margin requirements protect the wealth of the optimists, so that the over-optimistic agents may nonetheless survive. ${ }^{33}$

\section{Beyond dispersions in beliefs}

Heterogeneous expectations are necessary but not sufficient for pseudo-wealth to have large macroeconomic consequences. There must, for instance, be preferences such that individuals' behavior responds to these large differences in beliefs (e.g., individuals are not too risk aversethough no matter how risk averse, under the standard assumptions, they will engage in some trade, so pseudo-wealth and its fluctuations will play some role in macroeconomic volatility) and opportunities for those with different beliefs to engage in "trades."

And, while ceteris paribus an increase in pseudo-wealth would be expected to lead to an increase in consumption, the world is not one marked by ceteris paribus, so it is not inevitable that the induced fluctuations in aggregate perceived wealth lead to increased volatility of consumption. For instance, a financial innovation such as the creation of a market for bets in a context of heterogeneous beliefs will lead to increases in expected wealth. On its own, that will tend to

\footnotetext{
${ }^{33}$ Dosi et al. (2020) and Siniskaya and Tesfatsion (2015) have recently demonstrated that what might seem "better" learning processes-using more sophisticated estimation processes compared to more myopic expectationsactually result in poorer systemic performance.
} 
increase consumption. But it will also increase wealth volatility. ${ }^{34}$ The increased volatility will tend to increase precautionary savings. Thus, it is possible that an event, or other change in the economy that leads to an increase in aggregate pseudo-wealth, not lead to an increase in aggregate consumption. ${ }^{35}$ But empirically, it is plausible that, at least in many instances, the wealth effects dominate over the precautionary savings effects, and Guzman and Stiglitz (2020a) develop a model in which that is the case. ${ }^{36}$

With more general models of decision making under uncertainty, it is plausible that there may be asymmetric responses to increases in dispersions in beliefs associated with especially deep economic downturns - where precautionary behavior inhibits undertaking even small bets with positive expected gains, as individuals demand greater "flexibility" to respond to the unknown future (Kreps $(1979,1992))$ - and increases in dispersion in beliefs associated with an economic boom/price bubble, where more optimistic individuals/less risk averse individuals take advantage of differences in beliefs to engage in trades which increase pseudo-wealth and amplify the bubble. ${ }^{37}$

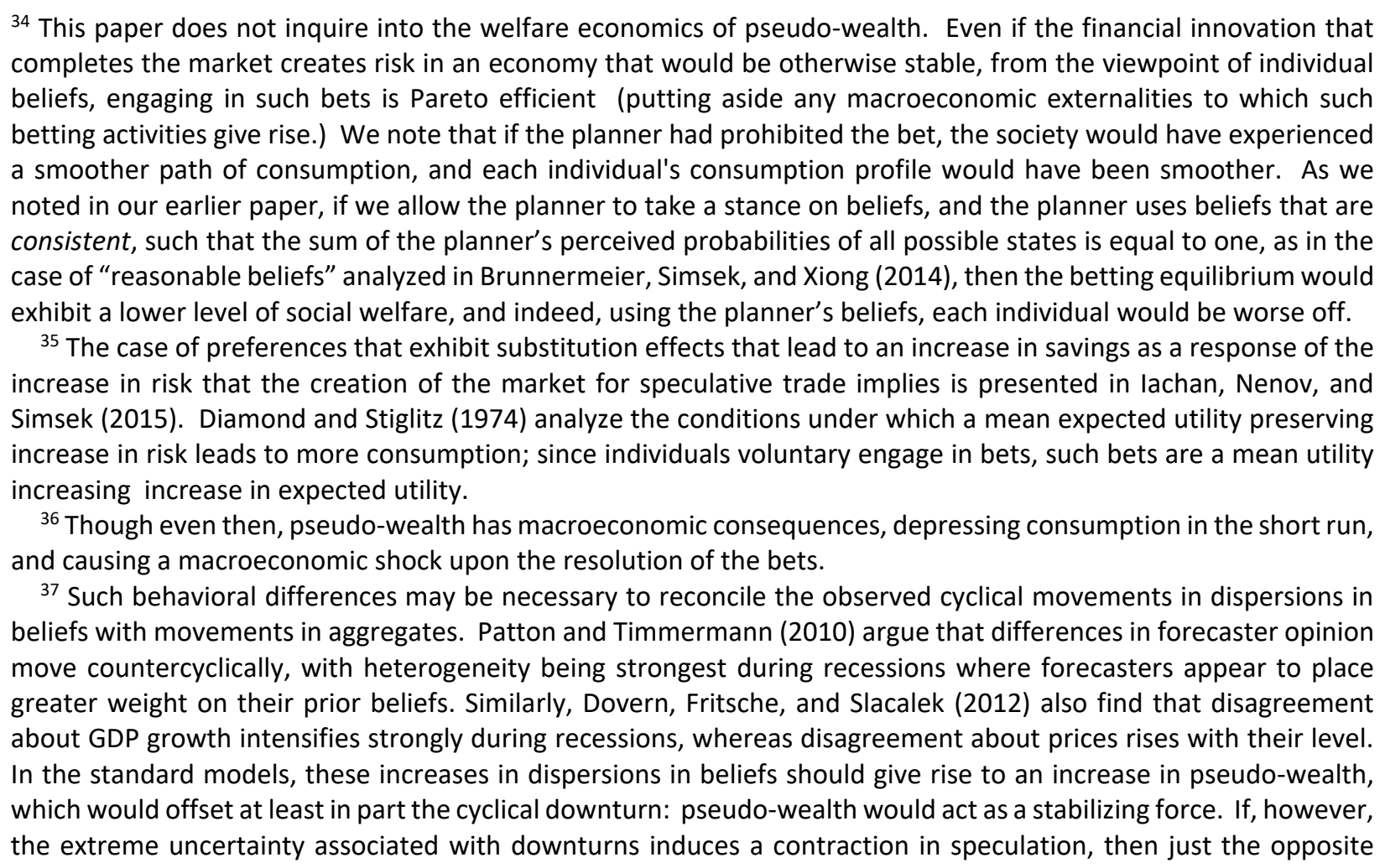




\section{Pseudo-wealth and macroeconomics: the amplification of fluctuations}

The previous section argued that it is not inevitable that creation of a new betting opportunity in the presence of disperse beliefs leads to a burst in aggregate demand, to be followed by a decline when the event on which the bets have been made gets "resolved," though even when it does not lead to an increase in aggregate demand, it will in general lead to an increase in the volatility of aggregate consumption. ${ }^{38}$

This goes against the prior prevailing presumption, that heterogeneity beliefs might help stabilize the economy: If cyclical variations were caused by fluctuations in investment, and investment were driven by equity prices (Tobin's q), and there were no restrictions on short sales, ${ }^{39}$ then counterviews could moderate fluctuations in q and stabilize the economy.

In this section, we explain in greater detail the role of pseudo-wealth in amplifying fluctuations, a role which is asymmetric both in the channels through which it operates and possibly in magnitude with respect to large positive and negative shocks.

Consider first negative shocks. Major events, such as the failure of Long-Term Capital Management, the terrorist attacks of September 11, 2001, and the fall of Lehman Brothers, are associated with increased with increased dispersion in beliefs (Carlin, Longstaff, and Matoba, 2014), but these are also events that make the environment more uncertain. The net effect on the extent of "betting" is ambiguous; there could be a decrease in "betting".

But while in the context of these adverse shocks, the new dispersion of beliefs may not give rise to new pseudo-wealth-were it to do so, it would help counter the downward movement of the

could occur; and this is especially so once the possibility of negative pseudo-wealth noted earlier is taken into account.

${ }^{38}$ That is, even if the increase in pseudo-wealth that follows from the increased dispersion in beliefs does not translate into increased consumption in the short run, it is still the case that when the bets get resolved, aggregate wealth declines, and with the decline, so do aggregate consumption.

${ }^{39}$ This is an important restriction, as we have already noted. 
economy-there is still a change in pseudo-wealth associated with pre-existing contractual arrangements: the adverse shock can give rise to negative pseudo-wealth, as creditors' beliefs about being repaid diminish more strongly than debtors' beliefs about making repayments.

On the other hand, moments of positive shocks-associated with the discovery of new technologies or the opening of new markets-may be associated not just with increased dispersion in beliefs, but also more confidence (and as a host of writers have emphasized, including Knight, Keynes, and Kindleberger, more confidence than they should have, based on history), at least on the part of many market participants, leading in turn to significant increases in pseudo-wealth. Thus, pseudo-wealth may amplify the effects of technology. (So too, when it is simply "animal spirits" that give rise to a boom in the economy. )

To illustrate this point, suppose that there is an innovation that increases the expected wealth of the society due to its (expected) effects on the real economy, but that given the different beliefs of market participants concerning the magnitude of the benefits, it also creates opportunities for speculative trading ("betting"). Suppose that the permanent income hypothesis holds. The "betting" opportunities would lead each market participant to believe she is even wealthier, amplifying the effect of the innovation on the aggregate spending.

Although the effects of variations in pseudo-wealth on spending and savings decisions will likely be concentrated on the segment of the society that experiences those variations, there may be aggregate demand effects-for instance, variations in pseudo-wealth could affect the demand for fixed assets such as land and housing, thus affecting the constraints of other agents that do not experience a direct variation in the component of their perceived wealth that is pseudowealth. ${ }^{40}$

\footnotetext{
40 These are all examples of macroeconomic externalities, the importance of which has recently become widely recognized (cf. for instance Greenwald and Stiglitz (1986), Aoki (1998), Lorenzoni (2008), Bianchi (2011), Jeanne and Korinek (2019), Korinek (2018) Dávila and Korinek (2018)), and Farhi and Werning (2016).
} 
Thus, not only is pseudo-wealth a potentially important determinant of the macro-economic state of the economy at each moment of time, but it may also play a role in at least some macroeconomic fluctuations.

In this section we have shown that heterogeneous beliefs may, or quite plausibly do, amplify economic fluctuations-a perspective that stands in marked contrast to the prevailing view that differences in views can play a role in dampening cycles.

\section{Pseudo-wealth as a source of fluctuations}

While pseudo-wealth can thus amplify fluctuations arising from other sources, in some circumstances pseudo-wealth can be the source of the fluctuation, rather than just an amplifier. That would be so, for instance, if there were a purely financial innovation, which did not affect the actual wealth capacity of the economy but only provided further opportunities for "betting."

Moreover, we have explained how positive shocks in particular can give rise to pseudo-wealth in excess of the real wealth of the economy, in which case it is inevitable that plans of individuals and firms of at least some individuals cannot be realized: in aggregate, for instance, planned aggregate consumption exceeds the potential of the economy. A sudden realization of this would itself represent a shock to the economic system, precipitating possibly a crisis or a severe downturn.

More generally, the dynamics of pseudo-wealth may play an important role in every stage of the cycle. The fact that increases in pseudo-wealth and hence consumption may track the optimism of the more optimistic members of society leads to social contagion: those optimistic beliefs, validated, as it were, by the stronger than expected performance of the economy, lead others to share in that optimism. The fact to that the increase in pseudo-wealth gets reflected in an increase in market prices ${ }^{41}$, increasing the ability and willingness to consume, investment, borrow, and lend, provides further amplification.

\footnotetext{
${ }^{41}$ See the analysis of Section 1 or the earlier discussion of Geanakopolis' leverage cycle.
} 
When the bubble breaks, there is heightened uncertainty, and while the dispersion of views about the breaking of the bubble, say, has been eliminated-leading to a sudden decrease in pseudo-wealth-there are new potential sources of dispersions of beliefs, potentially giving rise to renewed pseudo-wealth. But at that moment, heightened uncertainty prevails, and hence that potential is not realized. Rather, the change in pseudo-wealth is associated with existing contracts: differences in perceptions in the likelihood of repayment of current debts; and the heightened disparity in those perceptions leads to a marked increase in negative pseudo-wealth, deepening the economic downturn.

\section{An Empirical agenda}

An important question is, how significant is pseudo-wealth in practice either as an amplifier or a source of cyclical fluctuations? Our claim is not that variations in disparities of beliefs always gives rise to macroeconomic fluctuations or that all fluctuations are due to variations in pseudowealth; it is only that increases in the disparity of beliefs may be, and sometimes are, both a source of fluctuations and an amplifier, helping explain both the existence and magnitude of fluctuations in the economy that are hard to trace to other shocks, such as those related to technology.

Answering this question requires a careful empirical investigation-a step that we do not take in this paper. That empirical analysis would require, in the first place, more data on beliefs and the dispersion in those beliefs, and further empirical studies linking beliefs and behavior, and the behavior of individual agents and macroeconomic outcomes. We have argued, moreover, that pseudo-wealth may work differently, through different channels, in booms and in busts, so that any robust investigation of the relationship between pseudo-wealth and macroeconomic fluctuations has to investigate separately behavior under these different circumstances. So too, changes in pseudo-wealth may play a more important role for individuals in some circumstances than in others, and an empirical research agenda has to identify the circumstances in which it plays an important role, and whether, even if it plays an important role for some individuals, 
whether it does so in sufficient magnitude for a sufficiently large number that it has macroeconomic consequences.

Suppose that a survey was specifically designed to test the implications of the pseudo-wealth theory. The critical question is what data should be obtained from such a survey. We have explained that the magnitude of "betting" depends not only on the disparity of beliefs and the confidence of market participants in their beliefs, but also on their being markets that make "betting" possible. We have also explained that the consequences of pseudo-wealth and its variability depend on the effect of pseudo-wealth on spending decisions. That also depends on the agents' preferences, their degree of risk aversion, and their perceptions of risk. Thus, the surveys have to be comprehensive enough to enable empirical work showing both the dependence of consumption on (perceived) wealth and on risk (i.e., the extent to which an increase in risk gives rise to precautionary savings). Ideally, we would have data from which we could infer the joint distribution of beliefs, including the confidence in those beliefs, and the preferences of the market participants that engage in speculative trade. Studies on consumption would identify separately the effects of an increase in pseudo-wealth and market wealth in determining individual behavior, and how those effects depend on risk aversion, risk perceptions, and market (credit and collateral) constraints ${ }^{42}$-and by adding up those effects across individuals, derive empirically an aggregate consumption function.

(Ascertaining the dependence of aggregate consumption on both market and pseudo-wealth are important to assess sustainability: We have emphasized that even market wealth may not move in tandem with increases in the economy's productive capacities when there are dispersions in beliefs, and changes in those disparities. So too, we have noted that the channels through which changes perceived wealth and market wealth affect macroeconomic activity differ, and that the relative importance of the two may differ markedly across individuals depending on their circumstances.)

\footnotetext{
${ }^{42}$ As we noted in section 1 , the impact of market wealth as opposed to perceived or pseudo-wealth operates largely through such constraints.
} 


\section{Concluding Comments}

A key motivation for this paper was explaining the magnitude of the volatility in aggregate demand-the seeming "excessive volatility." As we noted, by excessive volatility we mean changes today that cannot be explained by changes in the underlying state variables, such as technology or capital stock. Not only are there not changes in these variables large enough to account for observed variations in outcomes, but also, in standard theory, there are strong automatic stabilizers, buffers (like inventories and price adjustments) that help the economy absorb shocks.

Earlier research (Greenwald and Stiglitz, 1993, 2003) and Stiglitz (2016) emphasized the role of capital market imperfections (credit and equity rationing and other financial frictions), which can amplify shocks and result in their persistence. In Guzman and Stiglitz (2020a), we discuss still other explanations, related to "trend shocks" (Aguiar and Gopinath, 2007, or "sentiment shocks" (Angeletos and La'O, 2013). Beaudry and Portier (2004, 2006) and Jaimovich and Rebel (2008) present models where news of a future real shock delivered today has effects prior to the shock itself.

Here, we have explored another potential source of excessive macroeconomic volatility-the volatility in pseudo-wealth, the result in turn of changes over time in the magnitude of dispersion in beliefs and the ability and opportunities to engage in "effective bets" based on these differences. ${ }^{43}$ Of course, the winning of a bet is simply redistributive in nature-and in standard macroeconomics, redistributions are of second order importance-here we have argued that that is not the case, that pseudo-wealth has macroeconomic consequences. Moreover, because the beliefs and dispersion of beliefs can change quickly ${ }^{44}$, and accordingly, with active speculative

\footnotetext{
${ }^{43}$ Our analysis focuses on changes in a belief about a future outcome which is redistributive in nature-the winning of a bet-but the making of the bet has macroeconomic consequences because it increases aggregate perceived wealth.

${ }^{44}$ Tsiaplias (2020) uses inflations expectations data from more than 285,000 Australian consumers to argue that a significant group of consumers update their information set very rapidly, almost every quarter. Baker, McElroy, 
markets, the aggregate value of pseudo-wealth can change quickly, even though the underlying state variables do not, pseudo-wealth can easily give rise to volatility.

Economists have long recognized that expectations, beliefs, matter. It is obvious that animal spirits, untethered to reality, can give rise to marked changes in aggregate demand-irrational optimism to a boom and irrational pessimism to a bust. Economists in recent decades have perhaps too easily dismissed such irrationality; even if it is irrational, it may still be predictable, as the title of Dan Ariely's book suggests (Ariely, 2010). In section 3, we explained that such irrationality could persist and survive. Moreover, we have argued that the prevailing reaction of economists to notions of the economy being driven by animal spirits-going to the other extreme of rational expectations-is flawed: the world is not well described by stationary stochastic processes; the important events that animate life are rare and fundamentally unpredictable.

While there is an important research agenda explaining movements over time in beliefs about advances in technology or growth in the economy, from an analytic perspective, the task of explaining aggregate fluctuations by animal spirits is perhaps too easy: it is almost obvious that if investors or consumers suddenly believe that they are wealthier (that their future incomes are higher than they previously thought) they will spend more, and if there is a sudden burst of such expectations, aggregate demand can increase suddenly. ${ }^{45}$

Our focus here is on the macroeconomic implications of dispersion in beliefs. Central to our argument that dispersion matters-that say the additional consumption of those whose estimates are more optimistic is not just offset by the additional consumption of those whose estimates are more pessimistic-is not the usual argument of non-linear relationships, for which there is indeed ample evidence. The theory of pseudo-behavior provides a further and stronger argument: that through the creation of pseudo-wealth, an increase in dispersion of beliefs leads

and Sheng (2020) show data about macro forecasts consistent with a model in which visibly large shocks induce immediate and synchronized updating of information for inattentive agents.

45 There is an important literature which structures expectation formation through learning. See Evans and Honkapohja, 2001, Heymann and Sanguinetti, 1998, and Guzman and Howitt, 2015. 
to aggregate behavior that is consistent with beliefs that wealth is different from what it is, even when those beliefs are on average correct.

While we must await further research to quantitatively assess the role of pseudo-wealth in business fluctuations-and because pseudo-wealth interacts jointly with other variables giving rise to and amplifying shocks, we will never have a precise parsing of its role-the empirical and theoretical foundations of the economics of pseudo-wealth and its potential as a driver of macroeconomic activity have already been laid, with elements of the evidence presented here:

a) There are large dispersions in beliefs.

b) Such dispersions can persist, at least for a while; but the magnitude of dispersion can, and does, change over time.

c) Dispersions in beliefs will, under standard preferences, give rise to a variety of economic transactions which give rise to pseudo-wealth.

d) Given the set of financial relations in existence, a shock to the economic system can give rise to negative pseudo-wealth.

e) As the economy evolves, with expected and unexpected shocks and events, and with changes in markets and market opportunities, there will be fluctuations in the magnitude of pseudo-wealth that may not be closely tethered to changes in the real wealth of the economy or to market wealth.

f) Such changes naturally amplify economic booms, and we have also explained how they can also amplify downturns.

g) The disparity between aggregate pseudo-wealth and true wealth means that plans of individuals and firms cannot be realized, necessitating adjustments at times. Those adjustments can occur rapidly, and if so, this can precipitate a crisis or severe downturn. Thus, pseudo-wealth is not just an amplifier of other disturbances, but a source of disturbance itself.

h) More generally, changes in pseudo-wealth can give rise to large and rapid changes in aggregate demand, at a pace beyond the capacity of other price and quantity variables to adjust, giving rise, in turn, to unemployment; and the decentralized adjustment processes 
of the economy may be disequilibrating, or at least not quickly restore the economy to its full employment trajectory.

The fact that, at least at times, both the magnitude of dispersions in beliefs and of trades in assets changes with the (business) cycle implies that there is at least a potential, or even a likelihood, that at times fluctuations in pseudo-wealth play a significant role in at least some economic fluctuations. Variations in pseudo-wealth cannot just be treated as "noise."

If pseudo-wealth is as potentially important as we suggest, it has policy implications. Expanding the set of betting opportunities - in the way that financial liberalization and structured finance has allowed-may well increase the level and volatility of pseudo-wealth. Making short-sales easier, while it may reduce the volatility of market wealth, may increase that of pseudo-wealth. We have set forth conditions under which macroeconomic volatility may be more closely linked with one or the other.

This paper, furthermore, lays out a challenge to the standard models based on rational expectations and common knowledge. If there are differences in beliefs (a point clearly established by the evidence presented here), efficient markets will create opportunities for trades based on those differences in beliefs, and this will necessarily give rise to pseudo-wealth that can be empirically significant, that is, which has macroeconomic consequences. Observed trading behavior is consistent with these observations. Macroeconomic modeling based on micro-foundations needs either to incorporate pseudo-wealth or explain why the seemingly large discrepancies in beliefs do not give rise to significant pseudo-wealth and why the variations in the magnitude of pseudo-wealth would not be an important driver of fluctuations. To put it another way, any micro-founded macroeconomic theory that ignores pseudo-wealth must explain why beliefs and preferences are such or market constraints are such as not to give rise to significant pseudo-wealth. Macroeconomics modeling purporting to be based on microfoundations has to accordingly either explain: (a) why the evidence on dispersions in beliefs and changes in dispersions is wrong; (b) why individuals do not engage in trade based on those 
differences in beliefs; and/or (c) why there are not macroeconomic consequences to those trades. So far, the standard literature has ignored all of these aspects of this challenge.

Ultimately, this paper offers a theoretical contribution with testable implications that can be distinguished from the implications of other related and complementary models for explaining cyclical fluctuations. In some circumstances the pseudo-wealth can be the source of economic fluctuations, in others it can amplify fluctuations arising from shocks arising elsewhere in the economic system. Policies may affect both the extent of differences in beliefs and the magnitude of trade, and thus the extent to which those differences give rise to pseudo-wealth and to its fluctuations.

The paper also illustrates that even outside of a rational expectations model, one can identify regularities in behavior that help account for the nature of economic fluctuations. Even if every downturn or crisis is different, there are elements of commonality. 


\section{References}

Aguiar, M. and Gopinath G. (2007), 'Emerging Market Business Cycles: The Cycle is the Trend', Journal of Political Economy, 115(1), 69-102.

Akerlof, A. G. and Shiller R. J. (2015), Phishing for Phools: The Economics of Manipulation and Deception. Princeton University Press: Princeton, NJ.

Angeletos, G. M. and La'O J. (2013), 'Sentiments', Econometrica, 81(2), 739-779.

Ariely, D. (2010), Predictably Irrational: The Hidden Forces that Shape Our Decisions. Harper Perennial: New York.

Aumann, R. (1976), 'Agreeing to Disagree', The Annals of Statistics, 4(6), 1236-1239.

Bacchetta, P. and Van Wincoop E. (2006), 'Can Information Heterogeneity Explain the Exchange Rate Determination Puzzle?’ American Economic Review, 96 (3), 552-576.

Baker, S., McElroy T. and Sheng, X. (2020), 'Expectation Formation Following Large, Unexpected Shocks', Review of Economics and Statistics, 102, 287-303.

Bamber, L., Barron O. and Stober T. (1997), 'Trading Volume and Different Aspects of Disagreement Coincident with Earnings Announcements', The Accounting Review, 72(4), 575-597.

Banerjee, A. (1992), 'A Simple Model of Herd Behavior,' Quarterly Journal of Economics, 107, 797-817.

Beaudry, P. and Portier F. (2004), 'An Exploration into Pigou's Theory of Cycles', Journal of Monetary Economics, 51, 1183-1216.

Beaudry, P. and Portier F. (2006), 'Stock Prices, News and Economic Fluctuations', American Economic Review, 96(4), 1993-1307.

Beber, A., Breedon F. and Buraschi, A. (2010), 'Differences in Beliefs and Currency Risk Premiums', Journal of Financial Economics, 98, 415-438.

Bikhchandani, S., Hirshleifer D. and Welch I. (1992), 'A Theory of Fads, Fashion, Custom, and Cultural Change as Informational Cascades,' Journal of Political Economy, 100, 992-1026.

Bianchi, J. (2011), 'Overborrowing and Systemic Externalities in the Business Cycle,' American Economic Review, 101(7), 3400-3426.

Bildersee, J., Radhakrishnan S. and Ronen J. (1996), 'Dispersion of Analysts' Forecasts, Precision of Earnings, and Trading Volume Reaction,' International Review of Financial Analysis, 5(2), 99111.

Brunnermeier, M. K., Simsek A. and Xiong W. (2014), 'A Welfare Criterion for Models With Distorted Beliefs,' The Quarterly Journal of Economics, 129(4), 1753-1797. 
Cao, D. (2018), 'Speculation and Financial Wealth Distribution under Belief Heterogeneity', The Economic Journal, 128(614), 2258-2281.

Caplin, A. and Leahy J. (1993), 'Sectoral Shocks, Learning and Aggregate Fluctuations,' Review of Economic Studies, 60, 1065-1085.

Carlin, B. I., Longstaff F. A. and Matoba K. (2014), 'Disagreement and Asset Prices', Journal of Financial Economics 114(2), 226-238.

Chen, J., Hong H. and Stein J. C. (2001), 'Forecasting Crashes: Trading Volume, Past Returns, and Conditional Skewness in Stock Prices', Journal of Financial Economics 61(3), 345-381.

Clement, M. and Tse S. (2005), 'Financial Analyst Characteristics and Herding Behavior in Forecasting', Journal of Finance, 60, 307-341.

Dávila, E. and Korinek A. (2018), 'Pecuniary Externalities in Economies with Financial Frictions,' Review of Economic Studies, Oxford University Press, 85(1), 352-395.

Devenow, A. and Welch I. (1996), 'Rational Herding in Financial Economics', European Economic Review, 40, 603-615.

Diamond, Peter A., and Joseph E. Stiglitz, 1974. "Increases in risk and in risk aversion." Journal of Economic Theory 8, No. 3, 337-360.

Diether, K. B., Malloy C. J. and Scherbina A. (2002), 'Differences of Opinion and the Cross Section of Stock Returns,' The Journal of Finance, 57(5), 2113-2141.

Dosi, G., Napoletano M., Roventini A., Stiglitz J. E. and Treibich T. (2020) 'Rational Heuristics? Expectations and Behaviors in Evolving Economies with Heterogeneous Interacting Agents,' Economic Inquiry, 58(3), 1487-1516.

Dovern, J., Fritsche U. and Slacalek J. (2012), 'Disagreement Among Forecasters in G7 Countries,' The Review of Economics and Statistics, 94(4), 1081-1096.

Evans, George W., and Seppo Honkapohja, 2001. Learning and Expectations in Macroeconomics. Princeton University Press, Princeton, New Jersey.

Fair, R. (2020), 'Some Important Macro Points,' Oxford Review of Economic Policy Volume 36, Issue 3, Autumn, pp. 556-578.

Farhi, E. and Werning I. (2016), 'A Theory of Macroprudential Policies in the Presence of Nominal Rigidities,' Econometrica, 84(5), 645-1704.

Fetzer, T., Hensel L., Hermle J., and Roth C. (2020), 'Coronavirus Perceptions and Economic Anxiety,' forthcoming, Review of Economics and Statistics.

Fisman, R. and O'Neill M. (2009), 'Gender Differences in Beliefs on the Returns to Effort: Evidence from the World Values Survey', The Journal of Human Resources, 44(4), 858-870. 
Fostel, Ana and John Geanakoplos, 2012. "Tranching, CDS, and asset prices: How financial innovation can cause bubbles and crashes." American Economic Journal: Macroeconomics, 4(1), pp.190225.

Fostel, A. and Geanakoplos J. (2013), 'Reviewing the Leverage Cycle', Cowles Foundation Discussion Paper No. 1918.

Fuhrer, Jeff, 2017, "Expectations as a source of macroeconomic persistence: Evidence from survey expectations in a dynamic macro model," Journal of Monetary Economics, Volume 86, Pages 2235, ISSN 0304-3932, https://doi.org/10.1016/j.jmoneco.2016.12.003.

Gai, P., Haldane A. G. and Kapadia S. (2011), 'Complexity, Concentration and Contagion,' Journal of Monetary Economics, 58, 453-470.

Geanakoplos, J. (1989), 'Game Theory without Partitions, and Applications to Speculation and Consensus', Cowles Foundation Discussion Paper No. 914.

Geanakoplos, J. (2003), 'Liquidity, Default, and Crashes: Endogenous Contracts in General Equilibrium', in M. Dewatripont, L. P. Hansen and S. J. Turnovsky (eds.), Advances in Economics and Econometrics: Theory and Applications. Cambridge University Press: Cambridge.

Geanakoplos, J. (2010), 'The Leverage Cycle', in D. Acemoglu, K. Rogoff, and M. Woodford (eds.), NBER Macroeconomics Annual 2009, Volume 24. University of Chicago Press: Chicago.

Geanakoplos, J., Axtell R., Farmer J. D., Howitt P., Conlee B., Goldstein J., Hendrey M., Palmer N. M. and Yang C. (2012), 'Getting at Systemic Risk via an Agent-Based Model of the Housing Market', American Economic Review, 102(3): 53-58.

Gennaioli, N. and Shleifer A. (2018), A Crisis of Beliefs: Investor Psychology and Financial Fragility. Princeton University Press: Princeton, N.J.

Giglio, S., Maggiori M., Stroebel J. and Utkus S. (2019), 'Five Facts about Beliefs and Portfolios', National Bureau of Economic Research Working Paper No. 25744.

Greenwald, B. C. and Stiglitz J. E. (1986), 'Externalities in Economies with Imperfect Information and Incomplete Markets', Quarterly Journal of Economics, 101(2), 229-264.

Greenwald, B. C. and Stiglitz J. E. (1989), 'Toward a Theory of Rigidities', American Economic Review, 79(2), 364-69.

Greenwald, B. C. and Stiglitz J. E. (1993), 'Financial Market Imperfections and Business Cycles', Quarterly Journal of Economics, 108(1), 77-114.

Grossman, S. and Stiglitz J. E. (1980),' On the Impossibility of Informationally Efficient Markets', American Economic Review, 70(3), 393-408. 
Guzman, G. (2010a), 'An Inflation Expectations Horserace', in A Collection on the Versatility and Predictive Power of Survey Expectations Data, Finance and Economics Doctoral Dissertation, Columbia University, unpublished.

Guzman, G. (2010b), 'Sexonomics: Gender, Wealth, and Expectations in Financial Markets', in A Collection on the Versatility and Predictive Power of Survey Expectations Data, Finance and Economics Doctoral Dissertation, Columbia University, unpublished.

Guzman, M. and P. Howitt (2015), "Learning, Expectations, and the Financial Instability Hypothesis," in J. E. Stiglitz and M. Guzman (eds.), Contemporary Issues in Macroeconomics: Lessons from The Crisis and Beyond. Palgrave: London.

Guzman, M. and Stiglitz J. E. (2015), 'A Theory of Pseudo-wealth', in J. E. Stiglitz and M. Guzman (eds.), Contemporary Issues in Macroeconomics: Lessons from The Crisis and Beyond. Palgrave: London.

Guzman, M. and Stiglitz J. E. (2020a), 'Pseudo-Wealth and Consumption Fluctuations', forthcoming, The Economic Journal.

Guzman, M. and Stiglitz J. E. (2020b), 'Towards a Dynamic Disequilibrium Theory with Noise', Oxford Review of Economic Policy, Volume 36, Issue 3, Autumn, pp. 621-674

Hamermesh, D. (1985), 'Expectations, Life Expectancy, and Economic Behavior', Quarterly Journal of Economics, 100(2), 389-408.

Heymann, Daniel, and Pablo Sanguinetti, 1998. "Business Cycles from Misperceived Trends." Economic Notes: 205-232.

Hong, H. and Stein J. C. (1999) 'Differences of Opinion, Rational Arbitrage and Market Crashes', National Bureau of Economic Research Working Paper No. 7376.

lachan, F., Nenov P. and Simsek A. (2015), 'The Choice Channel of Financial Innovation', National Bureau of Economic Research Working Paper No. 21686.

Jaimovich, N. and Rebelo S. (2008), 'News and Business Cycles in Open Economies', Journal of Money, Credit and Banking, 40(8), 1699-1711.

Jeanne, O. and Korinek, A. (2019), 'Managing Credit Booms and Busts: A Pigouvian Taxation Approach', Journal of Monetary Economics, 107, 2-17.

Jiang, H. and Sun Z. (2014), 'Dispersion in Beliefs among Active Mutual Funds and the Cross-Section of Stock Returns', Journal of Financial Economics, 114(2), 341-365.

Kaufmann, D., and Scheufele, R, 2017. "Business tendency surveys and macroeconomic fluctuations," International Journal of Forecasting 33(4), pp 878-893.

Kiyotaki, N. and Moore J. (1997), 'Credit Cycles', Journal of Political Economy, 105(2): 211-248. 
Korinek, A. (2018), 'Regulating Capital Flows to Emerging Markets: An Externality View', Journal of International Economics, 111: 61-80.

Kreps, D. M. (1979), 'A Representation Theorem for "Preference for Flexibility"', Econometrica, 47(3), 565-577.

Kreps, D. M. (1992), 'Static Choice in the Presence of Unforeseen Contingencies', Economic Analysis of Markets and Games: Essays in Honor of Frank Hahn. MIT Press: Cambridge.

Kurz, Mordecai, 1994. "On the Structure and Diversity of Rational Beliefs." Economic Theory 4, 877-900.

Kurz, Mordecai, and Maurizio Motolese, 2001. "Endogenous Uncertainty and Market Volatility." Economic Theory 17, 497-544.

Li, D. and Li G. (2014), 'Are Household Investors Noise Traders: Evidence from Belief Dispersion and Stock Trading Volume,' Microeconomics: General Equilibrium \& Disequilibrium Models of Financial Markets eJournal.

Lorenzoni, G. (2008), 'Inefficient Credit Booms', The Review of Economic Studies, 75(3), 809-833.

Manski, C. F. and Straub, J. D. (2000), 'Worker Perceptions of Job Insecurity in the Mid-1990s: Evidence from the Survey of Economic Expectations', Journal of Human Resources, 35(3), 447-479.

Milgrom, P. (1981), 'An Axiomatic Characterization of Common Knowledge', Econometrica, 49(1), 219222.

Milgrom, P. and Stokey N. (1982), 'Information, Trade, and Common Knowledge', Journal of Economic Theory, 1, 17-27.

Neeman, Z. (1996), 'Common Beliefs and the Existence of Speculative Trade', Games and Economic Behavior, 16(1), 77-96.

Patton, A. J. and Timmermann A. (2010), 'Why do Forecasters Disagree? Lessons from the Term Structure of Cross-Sectional Dispersion', Journal of Monetary Economics, 57(7), 803-820.

Phelps, E. (1999), 'Behind this Structural Boom: the Role of Asset Valuations', American Economic Review, 89(8), 63-68

Pigou, A. C. (1926), Industrial Fluctuations. MacMillan: London.

Scheinkman, J. and Xiong W. (2003), 'Overconfidence and Speculative Bubbles', Journal of Political Economy, 111(6), 1183-1219.

Shiller, R. J. (2014), 'Speculative Asset Prices', American Economic Review, 104(6), 1486-1517.

Sinitskaya, E. and Tesfatsion L. (2015), 'Macroeconomies as Constructively Rational Games', Journal of Economic Dynamics and Control, 61(C), 152-182. 
Stiglitz, J. E. (1982), 'Information and Capital Markets', in W.F. Sharpe and C. Cootner (eds.), Financial Economics: Essays in Honor of Paul Cootner. Prentice Hall: New Jersey.

Stiglitz, J. E. (2010a), Freefall: America, Free Markets, and the Sinking of the World Economy. W.W. Norton: New York.

Stiglitz, J. E. (2010b), 'The Financial Crisis of 2007-2008 and its Macroeconomic Consequences', in S. Griffith-Jones, J. A. Ocampo, and J. E. Stiglitz (eds.), Time for a Visible Hand: Lessons from the 2008 World Financial Crisis, Initiative for Policy Dialogue Series. Oxford University Press: Oxford.

Stiglitz J. E. and Greenwald, B. C. (2003), Towards a New Paradigm in Monetary Economics, Cambridge University Press: Cambridge.

Stiglitz, J. E. and Weiss, A. (1981), 'Credit Rationing in Markets with Imperfect Information', American Economic Review, 71(3), 393-410.

Stiglitz, J. E. and Weiss, A. (1986), 'Credit Rationing and Collateral', in J. Edwards, J. Franks, C. Mayer, and S. Schaefer (eds.), Recent Developments in Corporate Finance. Cambridge University Press: New York.

Stiglitz, J. E. and Weiss, A. (1992), 'Asymmetric Information in Credit Markets and Its Implications for Macroeconomics', Oxford Economic Papers, 44(4), 694-724.

Trueman, B. (1994), 'Analyst Forecasts and Herding Behavior', The Review of Financial Studies, 7(1), 97124.

Tsiaplias, S. (2020), 'Time-Varying Consumer Disagreement and Future Inflation', Journal of Economic Dynamics and Control, 116(C).

Wolf, M. (2014), The Shifts and the Shocks. Allen Lane: London.

Zhang, J. and Liu, P. (2012), 'Rational Herding in Microloan Markets', Management Science, 58(5), 892912. 